\title{
TITLE:
}

\section{A long-term control scheme of cutting forces to regulate tool life in end milling processes}

$\operatorname{AUTHOR}(S)$ :

Ibaraki, Soichi; Shimizu, Takuya

\section{CITATION:}

Ibaraki, Soichi ...[et al]. A long-term control scheme of cutting forces to regulate tool life in end milling processes. Precision Engineering 2010, 34(4): 675-682

ISSUE DATE:

2010-10

URL:

http://hdl.handle.net/2433/126733

\section{RIGHT:}

@ 2010 Elsevier Inc.; この論文は出版社版でありません。引用の際には 出版社版をご確認ご利用ください。; This is not the published version. Please cite only the published version. 


\title{
A Long-term Control Scheme of Cutting Forces to Regulate Tool Life in End Milling Processes
}

\author{
Soichi Ibaraki*and Takuya Shimizu \\ Department of Micro Engineering, Kyoto University \\ Yoshida-honmachi, Sakyo-ku, Kyoto, 606-8501, Japan
}

\begin{abstract}
Numerous researches on cutting force control in end milling processes have been reported in the literature. There have been, however, very few practical applications actually employed in commercial products. The paper presents a simple, practically feasible and effective scheme to regulate the tool life through a long-term control of cutting force. Cutting force changes quickly occurring due to tool path geometry are suppressed using model-based feedrate scheduling. Cutting force is monitored only at tool path check points, set typically at intervals of several dozen meters. Since it does not require continuous full-time monitoring of cutting forces, a "cheaper" estimation scheme of cutting forces can be potentially employed. Feedback control focuses only on a long-term point-to-point regulation of cutting force, targeting tool life providing cutting for the given desired distance. The effectiveness of the present approach is experimentally investigated by an application example to contour-parallel cutting of hardened steel.
\end{abstract}

${ }^{*}$ Corresponding author: Address: Department of Micro Engineering, Kyoto University, Yoshidahonmachi, Sakyo-ku, Kyoto, 606-8501, Japan; phone: +81-75-753-5227; fax: +81-75-753-5227; email:ibaraki@prec.kyoto-u.ac.jp 


\section{Introduction}

In early '90s, a sintered carbide end mill with an ( $\mathrm{Al}, \mathrm{Ti}) \mathrm{N}$ coating was introduced into the manufacturing of dies and molds, which made it possible to directly machine pre-hardened steel of the hardness up to HRC60. By first performing heat treatment on raw steel and then machining it by using such a tool, die/mold making process can be significantly simplified, eliminating the needs for grinding or electric discharging machining processes. Particularly in the machining with such a tool, very careful process planning is crucial to perform safe, and productive machining.

To support even a non-expert machine operator to perform safe and high-productive machining, numerous research effort have been devoted to the autonomous determination of machining parameters. Among various parameters associated with machining processes, cutting force or torque is relatively easy to monitor, and they are directly connected to the tool condition. Cutting force control has been extensively studied since the '60s. It is clear that an abrupt increase of cutting force must be avoided since it may cause tool damage or unexpected progress of tool wear. On the other hand, if the cutting force is lower than its "appropriate" level, the machining efficiency may be improved by regulating it higher. This is a common idea in many past researches in this field.

A good review on cutting force control in end milling can be found in $[1,2,3,4,5]$. A majority of these works contains the application of adaptive feedback control techniques to machining processes, such as the self-tuning regulation (Masory and Koren [6]), the model reference adaptive control (MRAC) (Tomizuka et al. [7]), and the MRAC extended by Zero Phase Error Tracking Control (ZPETC) (Rober and Shin [8]). Despite the significant amount 
of researches, the most of them have been seen as just a laboratory-level demonstration of sophisticated control theories applied to machining processes [5], and its impact to the industry has been quite limited. Ulsoy and Koren [2] in 1993 and Liang et al. [1] in 2004 have stated a similar remark.

From the authors' view, three major reasons are, first, the difficulty of systematically integrating machining control in machine tools [1]; second, the cost of installing reliable sensors to monitor cutting forces; and third, insufficient user understanding of a benefit of installing real-time feedback control. Feedback control generally requires that cutting force be continuously monitored. Reliable sensors such as piezoelectric dynamometers are considered expensive for general use by many machine tool manufacturers and users. Guaranteeing sensor-less estimation reliability based on motor current is difficult in commercial implementation, especially in milling [9].

Furthermore, even more importantly, a practical advantage of installing real-time feedback control with such an extra cost is not clear to many users. As well as feedback control, model-based feedrate pre-scheduling has been also widely studied. If an exact process model for predicting cutting force from machining conditions could be found, machining conditions could be optimized a priori to regulate cutting force as required. The simplest cutting force model, assuming that cutting force is proportional to the material removal rate (MRR), was adopted in early works $[10,11]$. Some commercial CAM software use the MRR-based simulator to optimize NC program feedrate. Commercial software to perform this feedrate scheduling for constant-feedrate NC programs are also available. More complex mechanistic models of cutting force generation in milling have been also actively studied, and they can be used as a basis for feedrate scheduling. For example, Budak [12] used a nonlinear 
mechanistic model proposed by Altintas and Spence [13] to regulate peak cutting force, and showed that the model-based approach exhibited control performance similar to adaptive feedback control.

Feedback control is clearly advantageous in adaptability to unmodeled machining processes. In many practical applications, however, even the simplest MRR-based feedrate scheduling effectively suppresses cutting force changes. In such cases, the necessity of installing feedback control is not clear.

The objective of this research is to propose a new control scheme of cutting force in end milling processes with a particular focus on tool life regulation. An inherent problem with a model-based pre-scheduling of machining conditions is its poor adaptability to machining process changes. The most important process change is, in our opinion, the progress of tool wear. Therefore, we implement feedback control mainly focusing on observing and controlling the progress of tool wear. A high-cost sensor to monitor cutting forces is not an essential requirement in our approach.

Many past works on Adaptive Control with Optimization (ACO) for machining processes considered tool wear as a constraint in selecting machining conditions [1]. For example, the first attempt at ACO by Centner [14] maximized the MRR through changes in feedrate and spindle speed under a constraint on the progress of tool wear, assuming that an accurate model to estimate tool wear is available. The selection of machining conditions were later formulated as a multiple-variables, multiple-constraints optimization problem $[15,16]$. In such approaches, a constraint on tool wear is mapped into a constraint on a control variable or a control objective by using some process model. To our knowledge, an explicit control of tool life, or the machinable distance before reaching the end of tool life, has not been studied 
in the field of machining process control.

\section{Concept of the Proposed Cutting Force Control Scheme}

Figure 1 shows the trade-off between machining efficiency and tool life. Generally, speeding up material removal to enhance machining efficiency often shortens tool life, increasing tool cost, meaning that tool cost is often sacrificed for efficiency. Practical machining places various constraints on this relationship, for example, on machining time to meet the manufacturing deadline. Another example is where the entire workpiece is required to be machined using a single tool only, often common in die and mold machining.

Our proposal aims to autonomously conduct "optimal" processing (represented by • in Fig. 1) under the given arbitrary constraint on this trade-off relationship by explicitly controlling tool life.

Figure 2 illustrates the simplified concept of the proposed scheme. Its main features are summarized as follows:

- Cutting force changes quickly occurring due to tool path geometry are suppressed using model-based feedrate scheduling. Real-time feedback control to regulate such a short-term cutting force variation requires higher sensor cost, and its reliability will be a critical issue in practical implementations. Although it is crucial to suppress such a short-term variation to avoid possible tool damage, we consider that a simpler model-based feedrate scheduling approach is sufficiently effective.

- Feedback control focuses on a long-term control of tool life. Assuming that cutting force slowly increases as the tool wear progresses as illustrated in Fig. 2, its rate of 
increase is regulated by modifying the feedrate profile in process, with control targeting tool life providing cutting for the given desired distance.

- For this control objective, cutting force is monitored at each tool path check point, set typically at intervals of several dozen meters. Since continuous monitoring is not required, the estimation of cutting forces using "cheaper" sensors is more feasible in such an application.

It is to be emphasized that the present scheme mainly targets roughing operations for hardened steel. It thus only considers the application of a straight (radius) end mill. The surface finish of machined workpiece, deteriorated by the progress of tool wear, is not taken into explicit consideration in its control objective.

More details of tool wear estimation at check points will be presented in Section 3. The control scheme of tool life will be presented in Section 4. Sections 5 and 6 will present its experimental case studies.

\section{Estimation of Tool Wear Progress by Monitoring Cutting Forces}

\subsection{Correlation of cutting force to progress of tool wear}

In end milling processes, cutting force generally increases as the tool wear progresses [17]. In tool condition monitoring (TCM), algorithms to detect excessive tool wear from cutting force have been drawing attention in academia for years. A good review on TCM can be found in e.g. $[18,19,1]$. The control scheme presented in this paper is based on the assumption on the correlation of cutting force to the progress of tool wear. 
To experimentally demonstrate this correlation, a simple cutting test is first presented. Generally, the correlation of cutting force to tool wear strongly depends on tool, workpiece, and cutting conditions. The present experiment intends to demonstrate this correlation with the tool and the workpiece that will be used in case studies in this paper.

By using an $(\mathrm{Al}, \mathrm{Ti}) \mathrm{N}$ coated sintered carbide radius end mill of the diameter $6 \mathrm{~mm}$ (six flutes), straight side cutting on hardened steel workpiece (JIS SKD61 (HRC53)) was repeated in the following machining conditions: cutting direction: down cut, coolant: oil mist, spindle speed: $16,000 \mathrm{~min}^{-1}$ (cutting speed: $150.8 \mathrm{~m} / \mathrm{min}$ ), feedrate: $5,760 \mathrm{~mm} / \mathrm{min}$ (0.06 mm/tooth), axial depth of cut: $3.0 \mathrm{~mm}$, and radial depth of cut: $0.15 \mathrm{~mm}$. Figure 3 shows the wear width at one of tool edges measured visually by using an on-the-machine tool microscope. The wear width was measured at heights $0.3 \mathrm{~mm}$ and $3.0 \mathrm{~mm}$ from tool bottom. Note that $3.0 \mathrm{~mm}$ corresponds to the axial depth of cut. Figure 4 shows cutting forces (their mean values over one path) measured by using a piezoelectric three-component dynamometer (Kistler 9257B). Figure 5 shows photos of tool edge at cutting distances $0 \mathrm{~m}$ and $300 \mathrm{~m}$. At cutting distance $270 \mathrm{~m}$, the chipping was observed at two of six flutes. At $300 \mathrm{~m}$, the chipping was observed at five flutes.

The tool was broken at cutting distance about $310 \mathrm{~m}$. As is typical in high-speed cutting of hardened steel with a smaller radial depth of cut, Figs. 3 and 4 show that the progress of tool wear is strongly correlated to cutting force in the normal to feed direction. This result demonstrates the validity to estimate tool wear progress from cutting force in this particular case. 


\subsection{Monitoring of Cutting Forces at Check Points}

Check points are set on tool paths typically at intervals of several dozen meters. Since they can be set at arbitrary locations, we can choose the region where the estimation of cutting forces is relatively easy. For example, they can be set only in the middle of a straight line or an circular arc of certain length, where only steady-state cutting force can be observed. In such an application, it is more practically feasible to implement a control scheme based on "cheaper" sensors than piezoelectric dynamometers.

As an example, we employ the cutting force calculation that we developed using spindleintegrated displacement sensors [20], shown in Fig. 6. We used four inexpensive, contaminationresistant eddy-current displacement sensors (S1-S4). Cutting force imposed at a tool in the XY plane can be estimated from spindle displacement. Analogous approaches to cutting force estimation from spindle displacement have been studied by many researchers [21, 22, 23]. Generally, such an approach involves major issues - a critical one is the thermal influence. Motor heat may critically deform or displace a rotating spindle, which must be separated from displacement caused by cutting force. In many commercial machining centers, the spindle is thermally controlled by circulating coolant through cooling jackets. In on-off temperature control, thermal deformation is significantly influenced by its control period. Thermocouples must be installed in the spindle to calculate thermal displacement.

Although it may be difficult to ensure the reliability of such a scheme for continuous monitoring, it is more feasible in the application to point-to-point, discrete monitoring of cutting force. More detailed investigation of measuring performance of this scheme can be found in [20]. 
It is to be noted that the control scheme presented in this paper requires no cost for an additional sensor when cutting forces are estimated from armature current in feed drive motors [9]. Although commercial piezoelectric dynamometers have significant advantages in their accuracy, reliability and stiffness, such a lower-cost estimation scheme would be of more importance when practically effective process control is possible with it.

\subsection{Estimation of Tool Wear Progress}

Cutting force is dependent not only on the tool wear, but also on machining conditions or tool path geometries. To estimate the tool wear progress from cutting force, the influence of machining conditions and tool path geometries must be separated. It can be done by using a process model to relate machining conditions to cutting force. Many models have been proposed in the literature [4]. In this paper, we employ a simple experimental model proposed by Kakino et al. [24]. Its brief review will follow:

This model gives the cutting force in XY plane, $F$, as a function of $t_{m}$, the maximum undeformed chip thickness, and $L$, the arc length of cutting engagement (see Fig. 7, where $R_{d}$ : radial depth of cut, $r$ : tool radius, $f$ : feed per tooth, $\alpha_{e n}$ : engagement angle, and $R$ : curvature radius at cutting point) as follows:

$$
F=F_{0}+\beta_{1} X_{1}+\beta_{2} X_{2}+\beta_{11} X_{1}^{2}+\beta_{22} X_{2}^{2}+\beta_{12} X_{1} X_{2}
$$

where $X_{1}:=\frac{t_{m}-t_{m 0}}{\delta t_{m}}, X_{2}:=\frac{L-L_{0}}{\delta L} . t_{m 0}, \delta t_{m}, L_{0}$, and $\delta L$ represent constant central values. Kakino et al. [24] experimentally showed its good estimation performance especially in highspeed milling of harder materials. It must be emphasized that the choice of the model (1) is not in the main scope of this paper. Any models that exhibits good estimation performance 
for the given machining application can be used.

At the $k$-th check point, the coefficient $F_{0}$ in Eq. (1), denoted by $F_{0}(k)$, is calculated by using the measured cutting force, $F(k)$. All the other coefficients, $\beta_{1}$ to $\beta_{12}$, are assumed to be constant. The coefficient $F_{0}(k)$ can be seen as the normalized cutting force for machining conditions corresponding to $X_{1}=X_{2}=0$. It represents the influence of tool wear progress in cutting force, excluding the influence of tool path geometry and machining conditions. The coefficient $F_{0}(k)$ is referred to as the normalized cutting force hereafter.

\subsection{Correlation of normalized cutting force to tool life: experi- ments}

To experimentally investigate the correlation of the normalized cutting force and the tool life, simple cutting experiments are conducted. Table 1 shows common machining conditions. Straight side cutting is repeated in the same machining condition until the end of tool life is reached. Total four different machining conditions $(\mathrm{C} 1 \sim \mathrm{C} 4)$ are tested as shown in Table 2. The end of tool life was judged from the observation of damages on tool edges and chips.

Figure 8 shows cutting forces, measured by using a dynamometer, in five conditions. Then, measured cutting forces are converted to the normalized cutting force, $F_{0}(k)$, as shown in Fig. 9. While the cutting force at the end of tool life is significantly dependent on cutting conditions in Fig. 8, its variation became much smaller in Fig. 9. The end of tool wear is reached when it reaches about $300 \sim 400 \mathrm{~N}$ in all the cases. 


\section{Cutting Force Control to Regulate Tool Life}

Figure 10 illustrates the concept of the proposed control scheme. The first some distance (200 $\mathrm{m}$ in this example) is machined by using the initial feedrate profile. The cutting force is monitored at every check point. The level of the cutting force to reach the end of tool life is assumed to be given by preliminary experiments or from the database $(400 \mathrm{~N}$ in this example). At $200 \mathrm{~m}$, we can estimate that the end of tool life will be reached at the cutting distance about $700 \mathrm{~m}$. Suppose that the control objective is to machine the cutting distance of $1000 \mathrm{~m}$. To meet this requirement, the target profile of cutting force control is given as illustrated in Fig. 10. The feedrate profile is updated at every check point to regulate the cutting force to this profile.

The detailed algorithm to update feedrate profile is given as follows:

(1) At the $k$-th check point, measure the cutting force, $F(k)$.

(2) Evaluate the normalized cutting force, $F_{0}(k)$, from $F(k)$ and given $X_{1}(k)$ and $X_{2}(k)$ by solving Eq. (1):

$$
F_{0}(k)=F(k)-\beta_{1} X_{1}(k)-\beta_{2} X_{2}(k)-\beta_{11} X_{1}(k)^{2}-\beta_{22} X_{2}(k)^{2}-\beta_{12} X_{1}(k) X_{2}(k)
$$

(3) Estimate the normalized cutting force at the $(k+1)$-th check point, $\hat{F}_{0}(k+1)$, by linearly extrapolating $F_{0}(k-1)$ and $F_{0}(k)$ :

$$
\hat{F}_{0}(k+1)=F_{0}(k)+\frac{L(k+1)}{L(k)}\left(F_{0}(k)-F_{0}(k-1)\right)
$$

where $L(k)$ is the cutting distance from the $(k-1)$-th check point to the $k$-th check point.

(4) Update the feedrate, $f(k+1)$, such that the normalized cutting force at the $(k+1)$-th check point, $F_{0}(k+1)$, is regulated to its target level, $\tilde{F}_{0}(k+1)$. In this study, we employ 
the following simple law:

$$
f(k+1)=f(k)+K \cdot\left(\hat{F}_{0}(k+1)-\tilde{F}_{0}(k+1)\right)
$$

where $K$ is constant, representing a proportional gain.

(5) Modify the feedrate override between $k$-th and $(k+1)$-th check points, $O(k+1)$, by:

$$
O(k+1)=\frac{f(k+1)}{f(k)} \cdot O(k)
$$

The feedrate override is the multiplying factor to a feedrate profile in NC program. Many latest CNCs allow a user to input a signal of feedrate override through an external input interface.

Remark: The present simple scheme makes a couple of assumptions on machining process. First, the correlation of cutting force to the progress of tool wear is assumed to be preserved till the end of tool life. Secondly, the normalized cutting force is assumed to increase slowly, as the tool wear progresses, with no abrupt changes. This is the case only when nominal tool wear is dominant throughout the tool life with no chipping or other abrupt tool damages. Thirdly, the tool life is assumed to be negatively correlated to feedrate. In other words, it is assumed that lower feedrate would extend the tool life, while higher feedrate would shorten it, as is illustrated in Fig. 1. Clearly, these assumptions are not met in all machining processes. In typical high-speed machining of steel, however, these assumptions are often valid when machining conditions are properly set. This paper implicitly assumes that machining conditions are properly set such that the assumptions above are met. In the following sections, we will experimentally show the effectiveness of the present approach under such a typical process. 


\section{Experimental Case Study \#1: Preliminary Tests Ap- plied to Straight Cutting}

To demonstrate the proposed tool life control scheme, its application to a straight-path cutting by a straight end mill is first presented.

Major machining conditions are the same as those shown in Table 1. A side-cutting along a straight path is repeated until the end of tool life is reached, under the radial depth of cut, $0.3 \mathrm{~mm}$, and the spindle speed, $16,000 \mathrm{~min}^{-1}$. As a preliminary experiment, cutting tests were conducted without updating the feedrate (constant feedrate: 11,520 mm/min). Figure 11(a) ("Normalized cutting force under constant feedrate") shows the normalized cutting force, $F_{0}(k)$, measured at each check point. The tool was broken at the cutting distance $650 \mathrm{~m}$, when the normalized cutting force reached about $400 \mathrm{~N}$. The overall material removal rate was $20.7 \mathrm{cc} / \mathrm{min}$.

Two experiments were conducted with different control objectives:

(1) Test 1: The control objective is to extend the tool life to $1,000 \mathrm{~m}$.

(2) Test 2: The control objective is to minimize the machining time while ensuring the tool life longer than $650 \mathrm{~m}$.

In Test 1, Figure 11(a) ("Normalized cutting force under control") shows the normalized cutting force, $F_{0}(k)$. The feedrate was constant at $11,520 \mathrm{~mm} / \mathrm{min}$ until the cutting distance $200 \mathrm{~m}$, where the tool life was estimated to be $650 \mathrm{~m}$. Considering the control objective, the target cutting force is given as shown in Fig. 11(a) ("Target profile"), such that cutting force reaches $400 \mathrm{~N}$ at $1,000 \mathrm{~m}$. The feedrate updating started from this point. As shown in Fig. 11(a), the tool life was extended to 900 m. Figure 11(b) shows a feedrate override 
profile modified at each check point.

In Test 2, Figure 12(a) ("Normalized cutting force under control") shows the normalized cutting force. The cutting distance $650 \mathrm{~m}$ was machined without reaching the end of tool life. As shown in Fig. 12(b), the feedrate override was increased to $156 \%$ at maximum. The overall material removal rate was $23.3 \mathrm{cc} / \mathrm{min}$, improved by $13 \%$ compared to the constant feedrate case, while securing the tool life longer than $650 \mathrm{~m}$.

\section{Experimental Case Study \#2: Application to Contour- parallel Cutting}

The proposed scheme was then applied to contour-parallel tool paths shown in Fig. 13(a). Figure 13(b) shows check points. Tool paths in one layer have the total cutting length of $37 \mathrm{~m}$. A hardened steel workpiece (JIS SKD61, HRC53), is repeatedly machined from outermost to innermost path until the tool breaks or wears beyond use. Major machining conditions are the same as those shown in Table 1 , with the step-over distance, $0.3 \mathrm{~mm}$, and the spindle speed, $8,000 \mathrm{~min}^{-1}$. In this experiment, cutting force is monitored at each check point by using spindle-integrated sensors presented in Section 3.2.

As a preliminary experiment, cutting tests were conducted without updating the feedrate profile. The feedrate profile is scheduled by using the initial model (1) such that the predicted cutting force is regulated constant. Figure 14(a) ("Normalized cutting force with only feedrate scheduling") shows the normalized cutting force, $F_{0}(k)$, measured at each check point. More than 1,000 $\mathrm{m}$ cutting distance was machined before reaching the end of tool life. The end of tool life was reached when the normalized cutting force reached about 400 
$\mathrm{N}$. The tool was broken there.

In this experiment, the control objective is given to minimize the machining time while securing that more than $600 \mathrm{~m}$ can be machined before reaching the end of tool life. The observation of experimental results will follow:

(1) Suppression of short-term variation in cutting force by feedrate scheduling

Figure 15(a) shows a feedrate profile for one loop of tool path, pre-scheduled to regulate cutting force constant. The actual feedrate was measured from encoder signal in the machine's feed drives. The cutting force measured in the same path is shown in Fig. 15(b). The cutting force was estimated from the displacement of spindle as has been presented in Section 3.2. Displacement signals are sampled with the sampling frequency $1000 \mathrm{~Hz}$ through an analog anti-aliasing filter of the cut-off frequency $500 \mathrm{~Hz}$. Sampled signals are digitally processed by a low-pass filter of the cut-off frequency $20 \mathrm{~Hz}$, and then converted to the cutting force imposed on the tool.

For the comparison, Figs. 16(a) and 16(b) respectively show measured feedrate and cutting force under a constant command feedrate, $3,000 \mathrm{~mm} / \mathrm{min}$. It can be observed that the variation in cutting force, caused by the variation in curvature of tool path, can be significantly suppressed by feedrate scheduling.

(2) Determination of target cutting force profile

Figure 14(a) ("Normalized cutting force under control") shows the normalized cutting force under control. The feedrate profile was not updated until the cutting distance $200 \mathrm{~m}$, where the tool life was estimated to be $1,400 \mathrm{~m}$. The target cutting force is given as shown in Fig. 14(a)("Target profile"), such that cutting force reaches $400 \mathrm{~N}$ at $600 \mathrm{~m}$ to meet the control objective. 
(3) Result

Feedrate override was modified at each check point as shown in Fig. 14(b). The allowable upper limit of feedrate override was set at $160 \%$. The end of tool life was reached at cutting distance $600 \mathrm{~mm}$, where the tool was broken. The overall material removal rate was 2.7 $\mathrm{cc} / \mathrm{min}$. When feedrate updating was not used, it was $2.2 \mathrm{cc} / \mathrm{min}$. The overall time to machine the cutting distance $600 \mathrm{~m}$ was reduced by about 1 hour and 20 minutes by performing the proposed tool life control scheme.

\section{Conclusion}

This paper presents a long-term control scheme of cutting forces to regulate tool life in end milling processes. The present scheme can be summarized as follows: (1) The cutting force is monitored only at every "check point" set on the tool path. Since it does not require continuous full-time monitoring of cutting forces, a "cheaper" estimation scheme of cutting forces can be employed. (2) The proposed control scheme focuses on the control of tool life through long-term, point-to-point cutting force control. The effectiveness of the present approach is experimentally investigated by cutting experiments of hardened steel.

The application of the present scheme to different workpiece materials may require a better process model than the one used in this paper (Eq. (1)). The basic idea of this paper can be, however, applied to a large class of machining applications as long as the assumptions discussed in Remark in Section 4 are met. 


\section{Acknowledgement}

This work was in part supported by Osawa Scientific Studies Grants Foundation. The machining center used in the experiments presented in this paper is supported by the Machine Tool Technologies Re-search Foundation (MTTRF) via Equipment on Loan Award Program. 


\section{References}

[1] S. Y. Liang, R. L. Hecker, R. G. Landers, "Machining process monitoring and control: The state-of-the-art," Trans. of ASME, J. of Manufacturing Science and Engineering, 126-2, pp. 297-310, 2004.

[2] Ulsoy, A. G., Koren, Y. "Control of Machining Processes,", ASME J. of Dynamic Systems, Measurement, and Control, 115, pp. 301-308, 1993.

[3] Altintas, Y., Manufacturing Automation: Metal Cutting Mechanics, Machine Tool Vibrations, and CNC Design, Cambridge University Press, 2000.

[4] Matsubara, A., Ibaraki, S., "Monitoring and Control of Cutting Forces in Machining Processes: A Review," International Journal of Automation Technology, 3-4, pp. 445456, 2009.

[5] A. Matsubara, "Current Status and Trends of Monitoring and Control Technology in Machining Process," J. of the Society of Instrument and Control Engineers, 41-1, pp. 781-786, 2002 (in Japanese).

[6] O. Masory, Y. Koren, "Variable Gain Adaptive Control System for Turning," J. of Manufacturing Systems, 2, pp. 165-173, 1983.

[7] Tomizuka, M., Oh, J. H., and Dornfeld, D. A., "Model Reference Adaptive Control of the Milling Process,", Control of Manufacturing Processes and Robotic Systems, ASME Winter Annual Meeting, pp. 55-63, 1983. 
[8] Rober, S. J., Shin, Y. C., "Control of Cutting Force for End Milling Using an Extended Model Reference Adaptive Control Schemes", ASME J. of Manufacturing Science and Engineering, Vol. 118, pp. 339-347, 1996.

[9] S. Ibaraki, M. Sakahira, H. Saraie, A. Matsubara, Y. Kakino, "On the Monitoring of Cutting Forces in End Milling Processes - An Estimation Method based on Geometrical Combination of Force Vectors of Servo Motors and a Spindle Motor -," J. of the Japan Society for Precision Engineering, 70-8, pp. 1091-1095, 2004, (in Japanese).

[10] Wang, K. K., "Solid Modelling for Optimizing Metal Removal of Three-Dimensional NC End Milling," Journal of Manufacturing Systems, Vol. 7, No. 1, pp. 57-65, 1988.

[11] Yamazaki, K., Kojima, N., Sakamoto, C., Saito, T., "Real-Time Model Reference Adaptive Control of 3-D Sculptured Surface Machining," Annals of CIRP, Vol. 40, No. 1, pp. 479-482, 1991.

[12] Budak, E., "Improving Productivity and Part Quality in Milling of Titanium Based Impellers by Chatter Suppression and Force Control" Annals of CIRP, Vol. 49, No. 1, pp. $31-36,2000$.

[13] Altintas, Y., Engin, S., "End Milling Force Algorithms for CAD Systems", Annals of CIRP, Vol. 40, No.1, pp. 31-34, 2001.

[14] Centner, R., "Final Report on Development of Adaptive Control Technique for Numerically Controlled Milling Machining," USAF Technical Documentary Report, ML-TDR64-279. 1964 . 
[15] Koren, Y., "The Optimal Locus Approach with Machining Applications," Trans. of ASME, J. of Dynamic Systems, Measurement and Control, 111, pp. 260-267, 1989.

[16] Ivester, R., Danai, K., Malkin, S., "Cycle-Time Reduction in Machining by Recursive Constraint Bounding," Trans. of ASME, J. of Manufacturing Science and Engineering, 119, pp. 201-207, 1997.

[17] Colwel, L. V. "Real time computer diagnostics (A research tool for metal cutting)," Annals of CIRP, 28-1, pp. 49-52, 1979.

[18] A. G. Rehorn, J. Jiang, P. E. Orban, E. V. Bordatchev, "State-of-the-art methods and results in tool condition monitoring: a review," Int'l J. of Advanced Manufacturing Technology, 26, pp. 693-710, 2005.

[19] G. Byrne, D. Dornfeld, I. Inasaki, G. Ketteler, W. Konig, R. Teti. "Tool condition monitoring (TCM) - the status of research and industrial application," Annals of the CIRP, 44-2, pp. 541-567, 1995.

[20] Sarhan, A. A. D., Matsubara, A., Sugihara, M., Saraie, H., Ibaraki, S., Kakino, Y., "Monitoring Method of Cutting Force by Using Additional Spindle Sensors," JSME Int'l J., Series C, 49-2, pp. 307-315, 2006.

[21] Kim, J. H., Chang, H. K., Han, D. C., Jang, D. Y., "Cutting Force Estimation by Measuring Spindle Displacement in Milling Process, " CIRP Annals - Manufacturing Technology, 54-1, pp. 67-70, 2005. 
[22] Albrecht, A., Park, S. S., Altintas, Y., Pritschow, G., "High frequency bandwidth cutting force measurement in milling using capacitance displacement sensors," Int'l J. of Machine Tools and Manufacture, 45-9, pp. 993-1008, 2005.

[23] Auchet, S., Chevrier, P., Lacour, M., Lipinski, P., "A new method of cutting force measurement based on command voltages of active electro-magnetic bearings," Int. J. of Machine Tools and Manufacture, 44, pp. 1441-1449, 2004.

[24] Kakino, Y., Ohtsuka, H., Nakagawa, H., and Hirogaki, T., "NC Programming for Constant Cutting Force in Die Machining," Proc. of 2000 Int'l Conf. on Advanced Manufacturing Systems and Manufacturing Automation, pp. 471-475, 2000. 
Table 1: Common machining conditions.

\begin{tabular}{l|l}
\hline Machine & Vertical machining center \\
\hline Tool & $\begin{array}{l}\text { (Al, Ti)N coated sintered carbide } \\
\text { radius end mill }(\phi 6 \mathrm{~mm}, 6 \text { flutes })\end{array}$ \\
\hline Workpiece & JIS SKD61 (HRC53) \\
\hline Coolant & Oil mist \\
\hline Cutting direction & Down cut \\
\hline Coolant & Walter-solvent emersion \\
\hline Tool extension & $18 \mathrm{~mm}$ \\
\hline Axial depth of cut & $6 \mathrm{~mm}$ \\
\hline
\end{tabular}


Table 2: Machining conditions in tool wear tests.

\begin{tabular}{l|l|l|l|l|l}
\hline Name & $\begin{array}{l}\text { Spindle speed, } \\
\mathrm{min}^{-1}\end{array}$ & $\begin{array}{l}\text { Cutting speed, } \\
\mathrm{m} / \mathrm{min}\end{array}$ & $\begin{array}{l}\text { Radial depth } \\
\text { of cut, } \mathrm{mm}\end{array}$ & $\begin{array}{l}\text { Feedrate, } \\
\mathrm{mm} / \mathrm{min}\end{array}$ & $\begin{array}{l}\text { Feed per tooth, } \\
\mathrm{mm} / \text { tooth }\end{array}$ \\
\hline $\mathrm{C} 1$ & 8,000 & 150.8 & 0.3 & 2,900 & 0.060 \\
\hline $\mathrm{C} 2$ & 8,000 & 150.8 & 0.3 & 3,781 & 0.079 \\
\hline $\mathrm{C} 3$ & 16,000 & 301.6 & 0.5 & 7,680 & 0.080 \\
\hline $\mathrm{C} 4$ & 16,000 & 301.6 & 0.3 & 11,520 & 0.120 \\
\hline
\end{tabular}




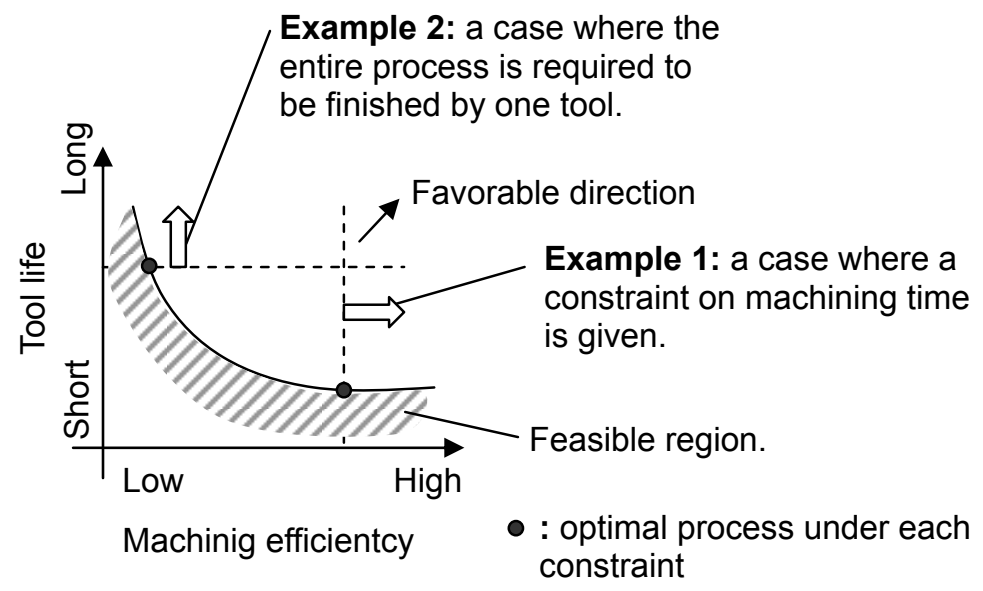

Figure 1: Trade-off between machining efficiency and tool life. 


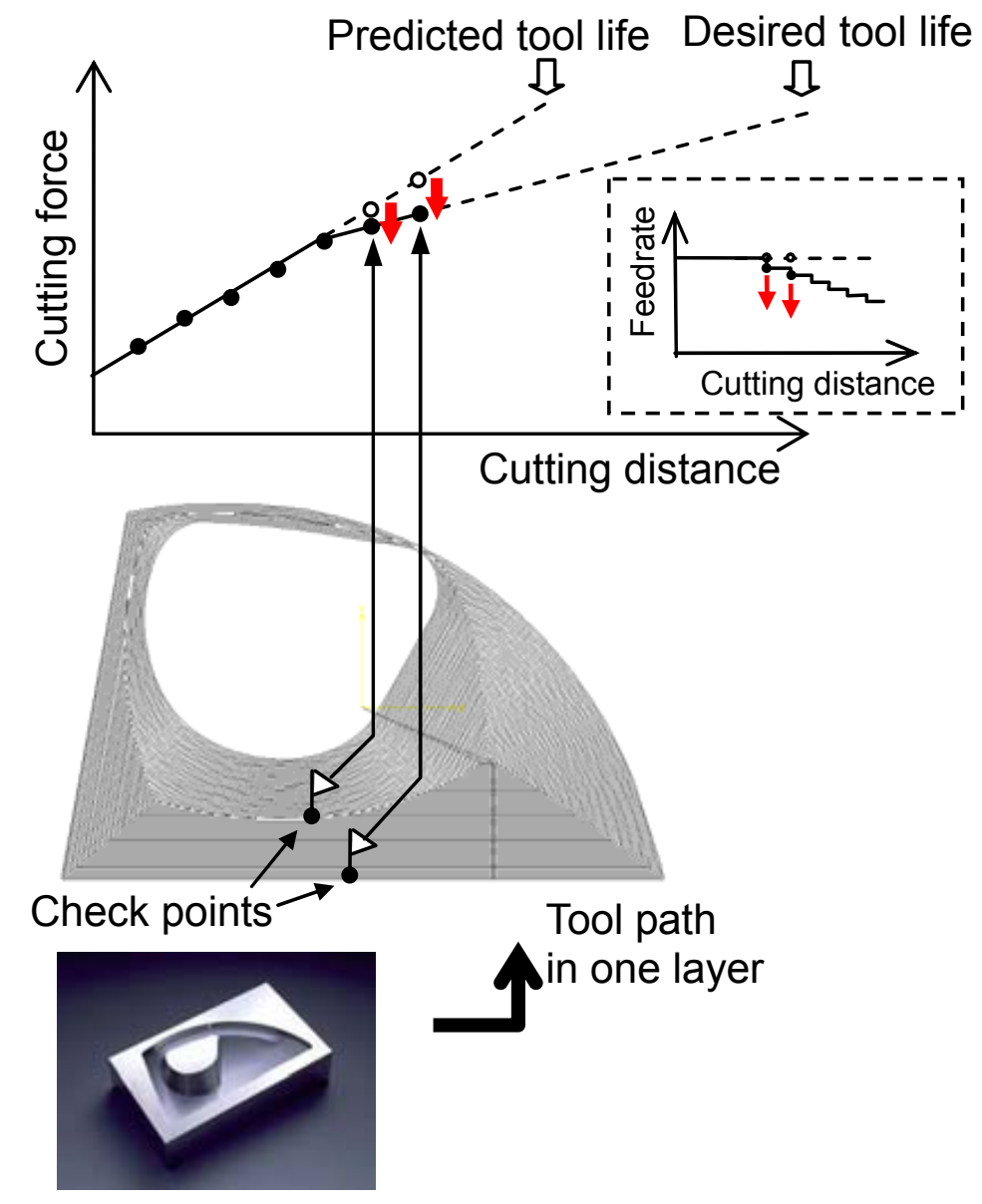

Figure 2: Concept of tool life control through cutting force control. 


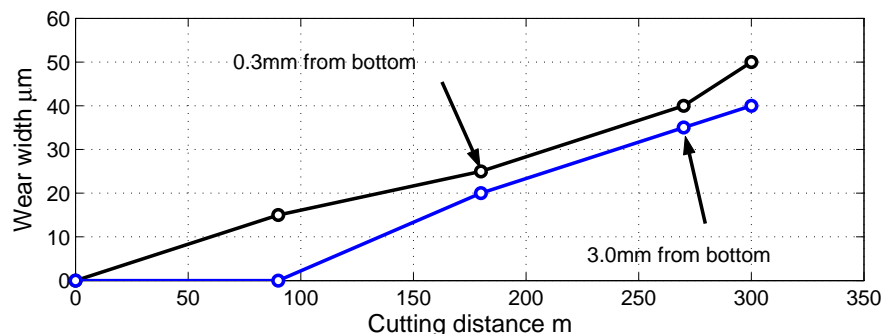

Figure 3: Wear width on a tool edge in the straight side cutting test (at heights $0.3 \mathrm{~mm}$ and 3.0 $\mathrm{mm}$ from tool bottom, where $3.0 \mathrm{~mm}$ corresponds to axial depth of cut). 


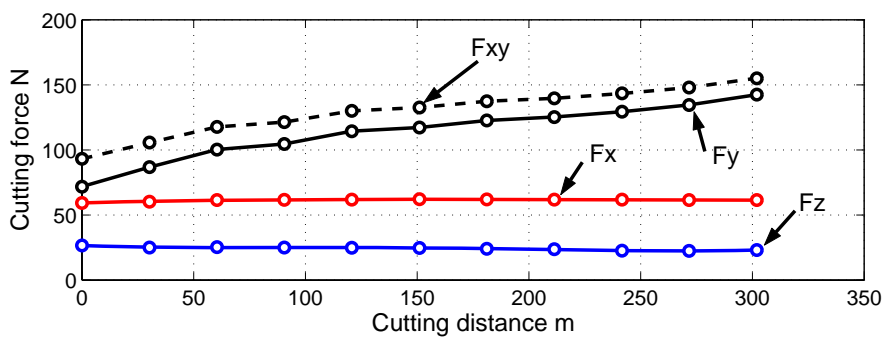

Figure 4: Cutting forces in the straight side cutting test $\left(F_{x}\right.$ : in feed direction, $F_{y}$ : in direction normal to feed, $F_{z}$ : in axial direction, $\left.F_{x y}:=\sqrt{F_{x}^{2}+F_{y}^{2}}\right)$. 


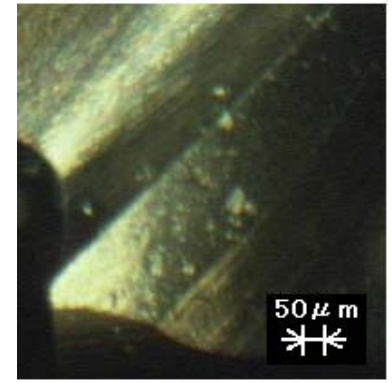

(a-1) tool bottom (cutting distance $=0 \mathrm{~m}$ )

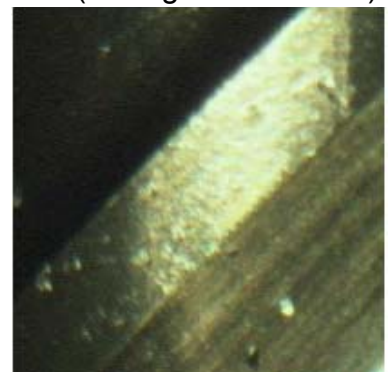

(a-2) $3.0 \mathrm{~mm}$ from tool bottom (cutting distance $=0 \mathrm{~m}$ )

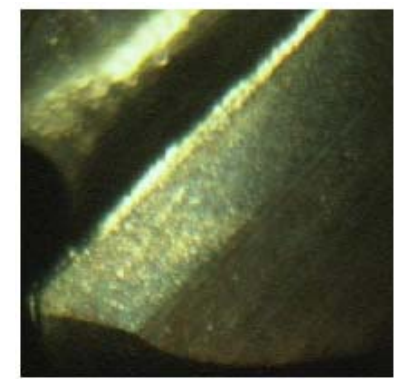

(b-1) tool bottom (cutting distance $=300 \mathrm{~m}$ )

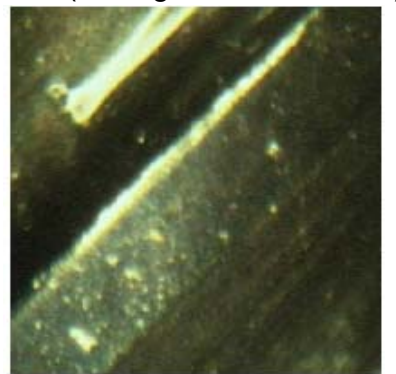

(b-2) $3.0 \mathrm{~mm}$ from tool bottom (cutting distance $=300 \mathrm{~m}$ )

Figure 5: Photos of flank face of a tool edge (3.0 mm corresponds to axial depth of cut). 


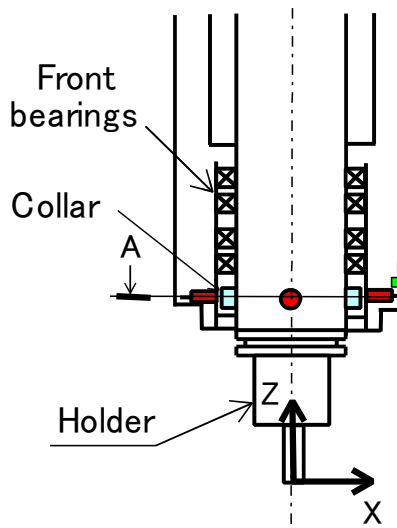

(a) Front view

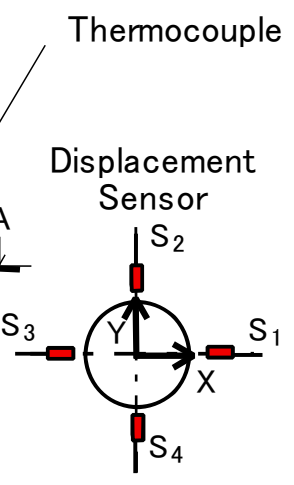

(b) A-A section

Figure 6: Spindle-integrated displacement sensor configuration for determining cutting force [20]. 


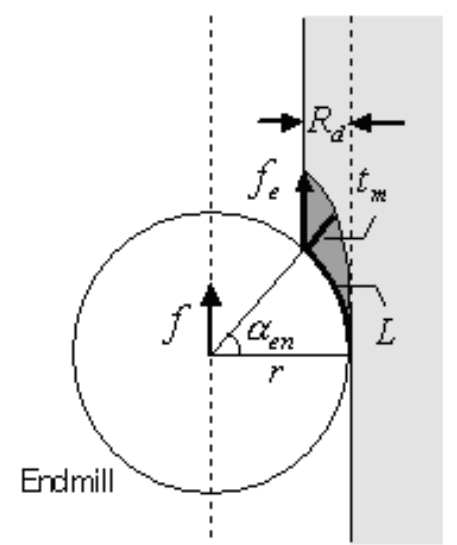

(a) On a straight path

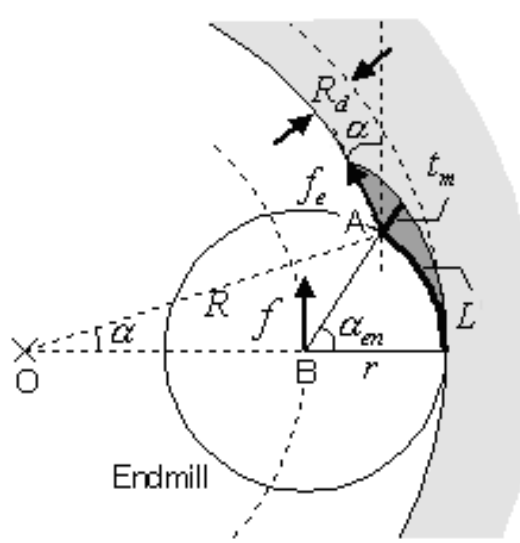

(b) On a circular path

Figure 7: Schematics of end milling process[24] 


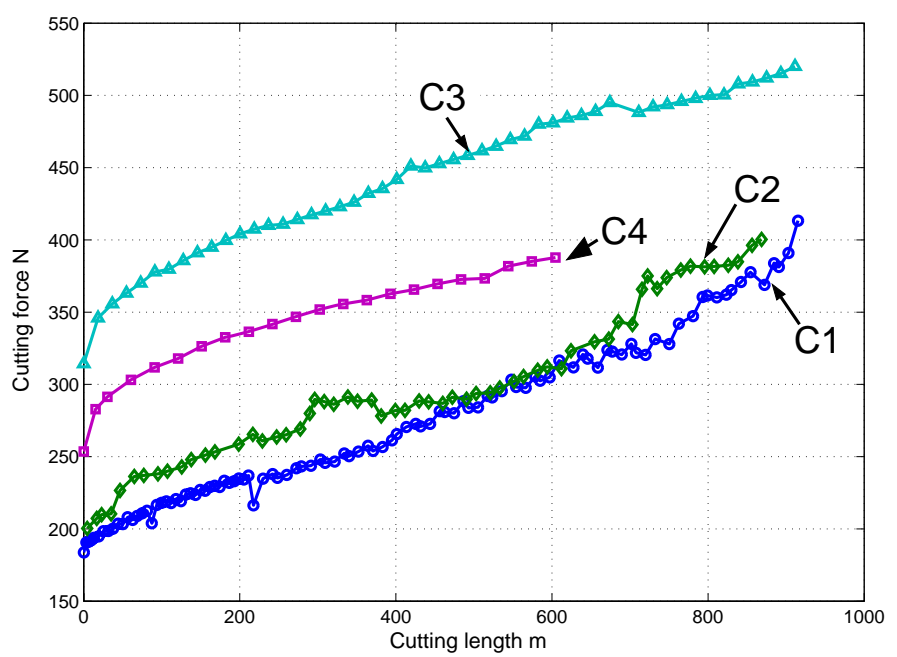

Figure 8: Comparison in measured cutting force (in the direction normal to the feed direction) until the end of tool life. 


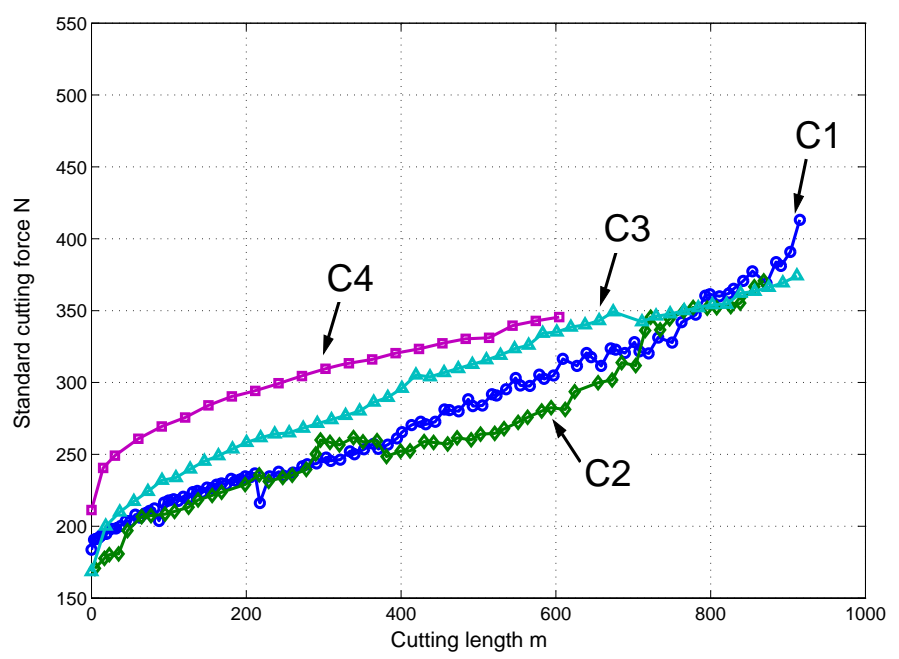

Figure 9: Normalized cutting force, $F_{0}(k)$, computed from measured cutting forces shown in Fig. 8. 


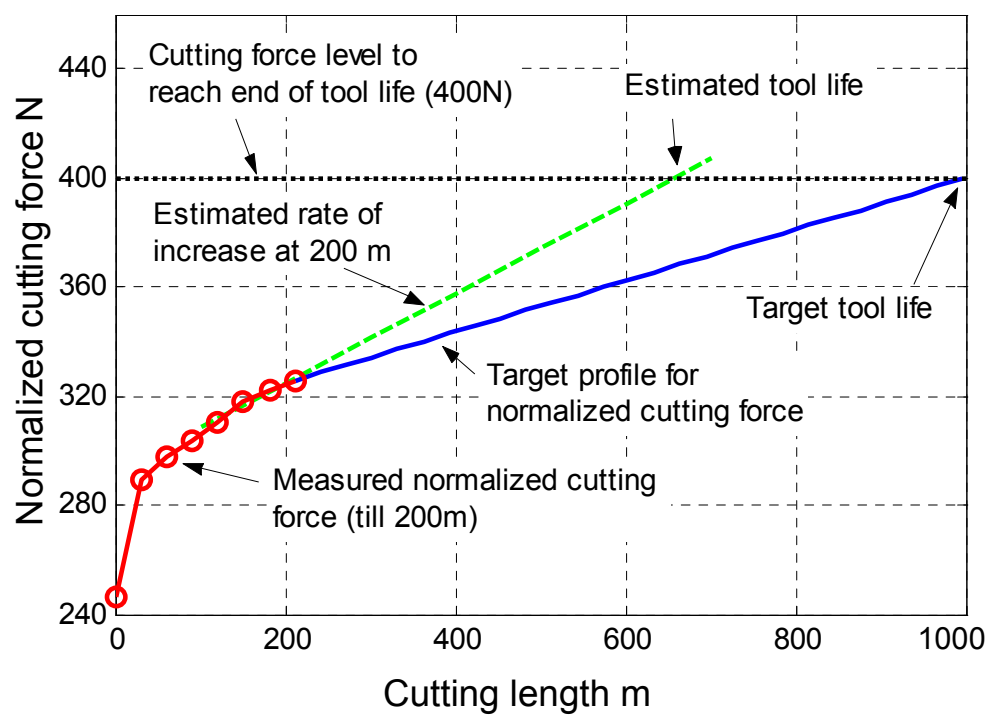

Figure 10: Concept of the determination of target profile for cutting force control 


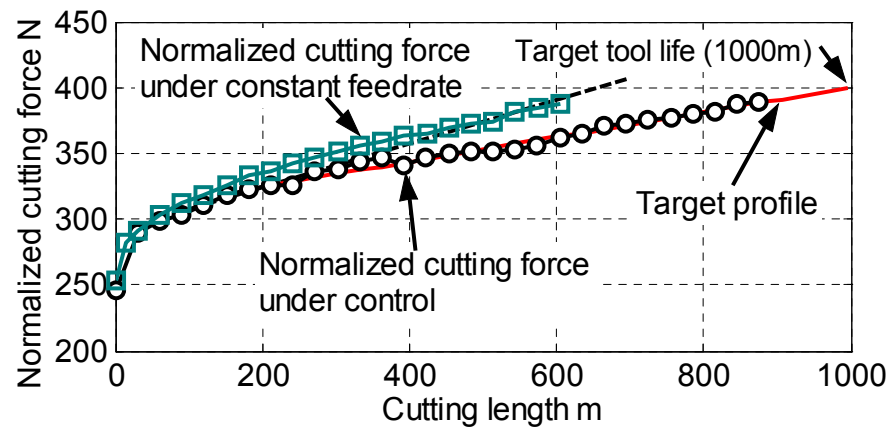

(a) Normalized cutting force with and without the proposed control.

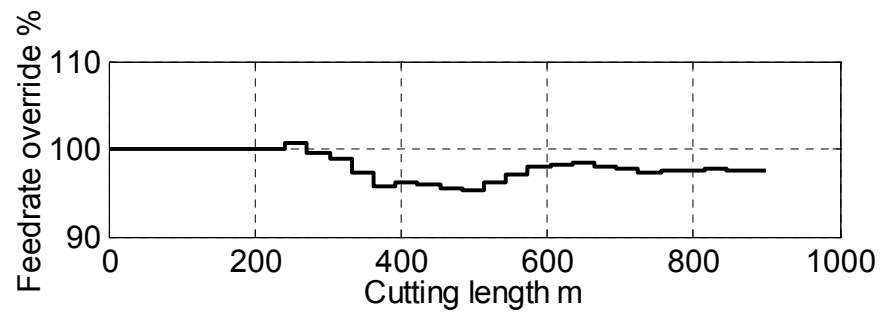

(b) Feedrate override under the proposed control

Figure 11: Test 1: Straight cutting with the control objective to extend the tool life to 1,000 m. 


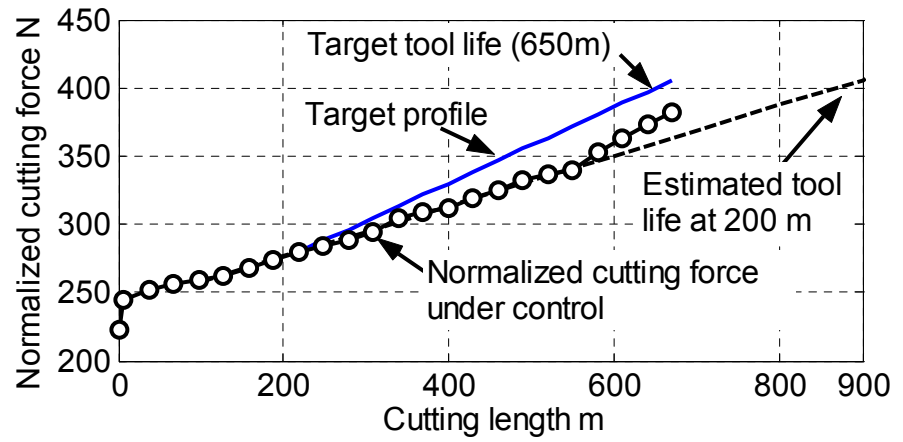

(a) Normalized cutting force under the proposed control.

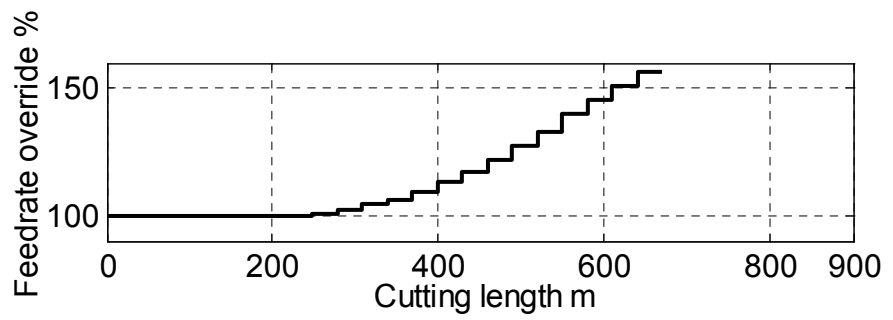

(b) Feedrate override under the proposed control.

Figure 12: Test 2: Straight cutting with the control objective to minimize machining time while ensuring tool life longer than $650 \mathrm{~m}$. 


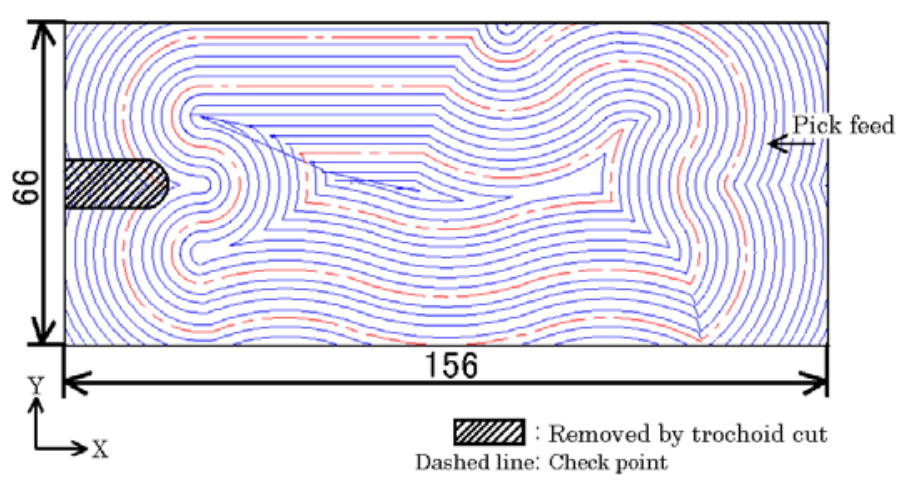

(a) Tool path (actual step-over is $0.3 \mathrm{~mm}$ )

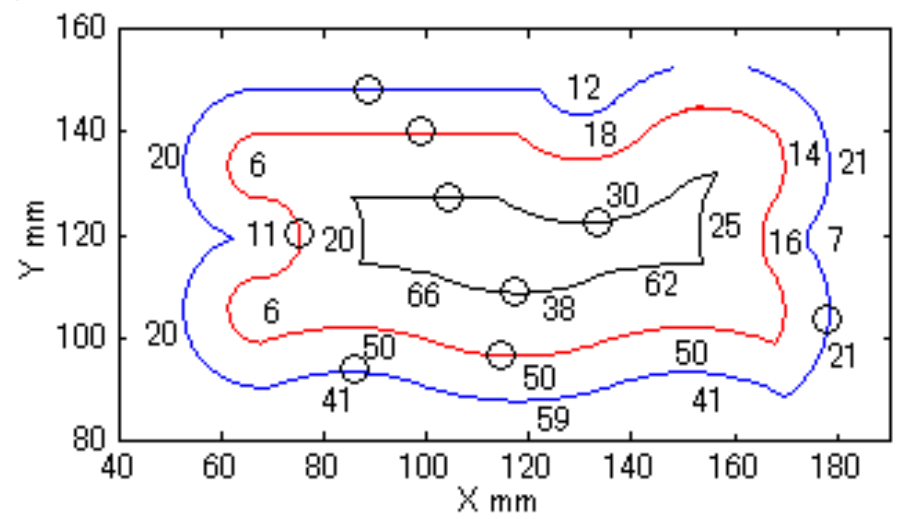

(b) Check points (numbers indicate curvature radius of tool path)

Figure 13: Tool path and check points in case study \#2. 


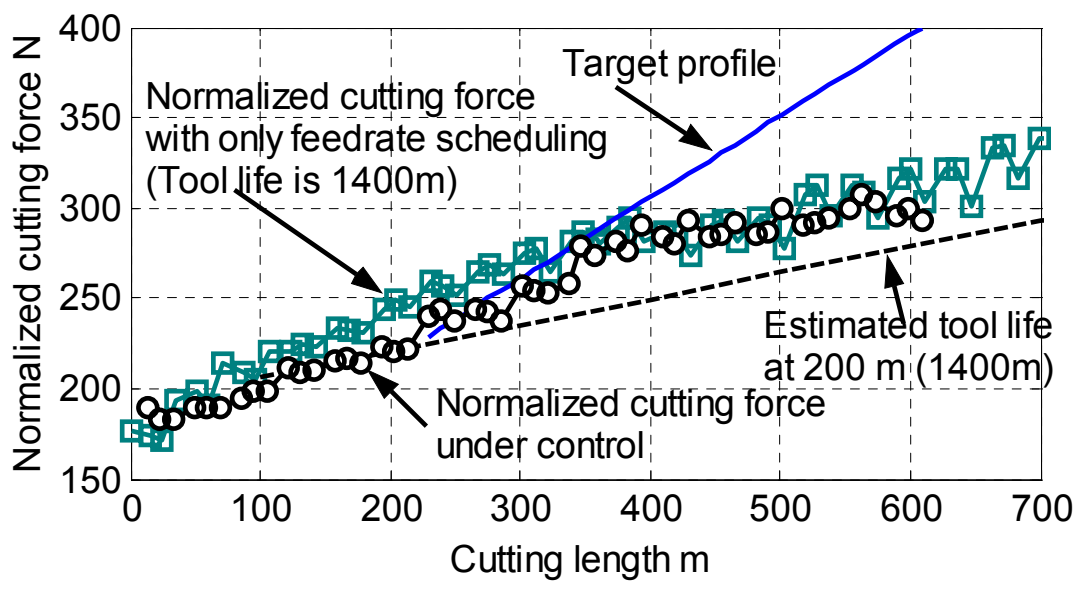

(a) Normalized cutting force with and without the proposed control.

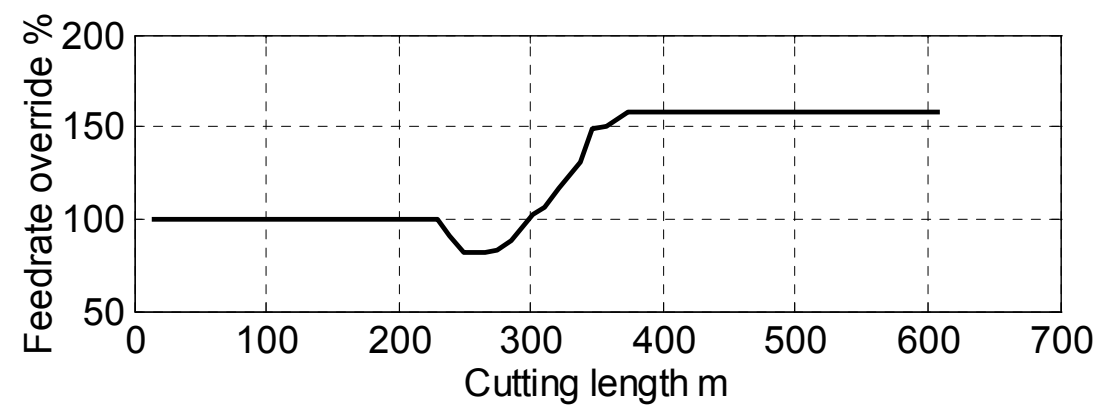

(b) Feedrate override under the proposed control

Figure 14: Case Study \#2 with the control objective to minimize machining time while securing that more than $600 \mathrm{~m}$ can be machined. 


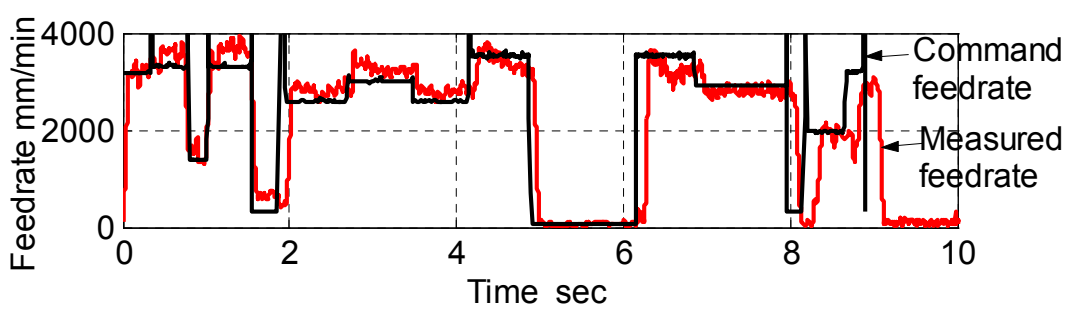

(a) Command and measured feedrate profiles.

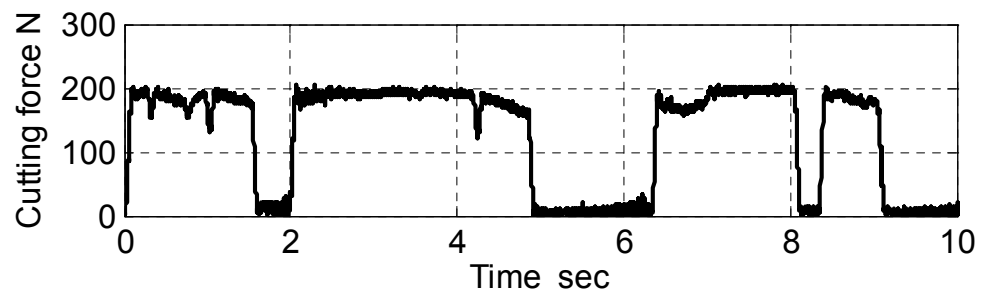

(b) Measured Cutting force.

Figure 15: Feedrate and cutting force for one loop of tool path at cutting length $15 \mathrm{~m}$ under feedrate scheduling. 


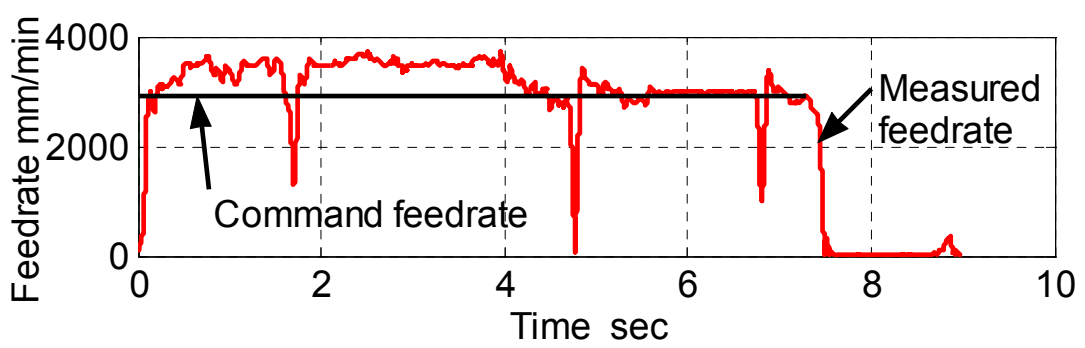

(a) Command and measured feedrate profiles.

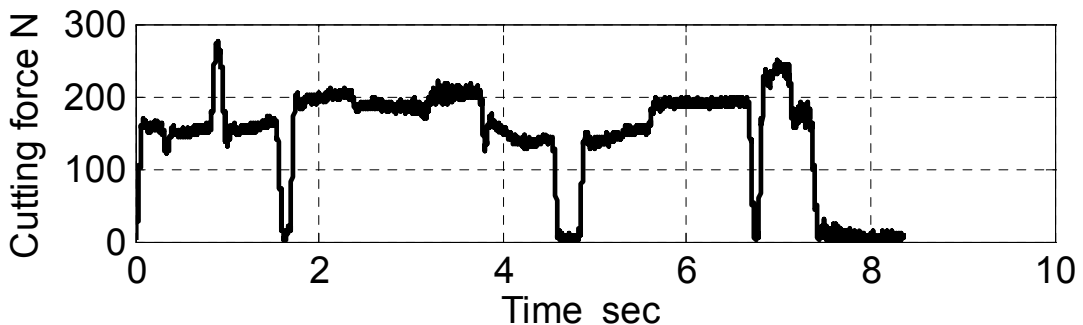

(b) Cutting force.

Figure 16: Feedrate and cutting force for one loop of tool path at cutting length $15 \mathrm{~m}$ under a constant feedrate. 